\title{
Experimental Study of Flow Boiling Using R134a in Multi Microchannels
}

\author{
R. Al-Janabi ${ }^{1,2}$, F. Coletti ${ }^{1}$, M.M. Mahmoud ${ }^{1,3}$, T.G. Karayiannis ${ }^{1}$ \\ ${ }^{1}$ Brunel University London \\ Uxbridge, Middlesex UB8 3PH, UK \\ Tassos.Karayiannis@brunel.ac.uk \\ ${ }^{2}$ University of Technology \\ Al Sina'a Street, Baghdad, Iraq \\ ${ }^{3}$ Zagazig University \\ 44519, Zagazig, Egypt
}

\begin{abstract}
This paper presents the results of an experimental investigation of flow boiling heat transfer in multi microchannel heat sink. The test section, $20 \mathrm{~mm}$ long and $15 \mathrm{~mm}$ wide, consisted of 26 rectangular microchannels $\left(350 \mu \mathrm{m}\right.$ wide, $630 \mu \mathrm{m}$ deep -i.e. $\mathrm{D}_{\mathrm{h}}$ $=450 \mu \mathrm{m}$ - and $200 \mu \mathrm{m}$ wall thickness) produced by CNC machining from an oxygen free copper block. Using R134a as a test fluid, the experiments were conducted at a system pressure of 7 bar, heat flux range $7.6-625.8 \mathrm{~kW} / \mathrm{m}^{2}$ and mass flux range $50-300 \mathrm{~kg} / \mathrm{m}^{2} \mathrm{~s}$. A high speed camera was used to capture the flow patterns. Four flow patterns were observed namely bubbly, slug flow/confined bubble, churn flow and annular flow as the heat flux gradually increased. Results show that the maximum heat transfer coefficient obtained is $35.52 \mathrm{~kW} / \mathrm{m}^{2} \mathrm{~K}$. The results also show that the heat transfer coefficient increased with heat flux and there was no mass flux effect. Relevant literature correlations predicting the heat transfer coefficient were evaluated against the current data.
\end{abstract}

Keywords: Multi-microchannels, R134a, Cooling of electronics, Flow boiling.

\section{Introduction}

Flow boiling in micro channels has been proven to be an effective method for dissipating high heat fluxes in several applications such as electronic and MEMS devices [1]. However, because of uncertainties that still exist in the fundamental understanding of key phenomena underlying heat transfer and fluid flow at the micoscale, there are currently no commercially available devices that exploit this technology. Uncertainties include the dominant heat transfer mechanisms [2-7] the effect of channel aspect ratio on heat transfer rates and flow patterns, the effect of channel length, the effect of surface roughness [8-10] and flow instabilities[11,12]. Karayiannis et al. [9] highlighted discrepancies in the findings of a number of studies in the literature leading to uncertainty in the correlations predicting the heat transfer coefficient and pressure drops. In fact, a number of studies in the literature report a dependency of the heat transfer coefficient on heat flux but not on mass flux and vapour quality [13-19] while others reported that the heat transfer coefficient increases with increasing mass flux and it is a function of vapour quality [4-20]. Moreover, only few studies exist on multi-channel configurations. Fayyadh et al. [21] conducted experiments to investigate heat transfer coefficient of R134a in a multi-microchannel heat sink. Using the same test facility as in this paper but with a different test section, they designed 25 rectangular micro-channels $(300 \mu \mathrm{mx} 700 \mu \mathrm{m}), \mathrm{D}_{\mathrm{h}}=420 \mu \mathrm{m}$, for 6.5 bar system pressure, heat flux of $11.46-403.1 \mathrm{~kW} / \mathrm{m}^{2}$ and mass flux of $50-300 \mathrm{~kg} / \mathrm{m}^{2} \mathrm{~s}$. The results, showed that the heat transfer coefficient, $h$, increased with heat flux, $q^{\prime \prime}$, while there was no mass flux effect.

The study presented here aimed at conducting experiments on flow boiling heat transfer of R134a in a rectangular multi-microchannel heat sink for varying heat and mass flux and fixed system pressure. Furthermore, the study aimed at capturing flow patterns during the experiments using a high speed camera connected to a microscope. Existing heat transfer correlations were compared and evaluated using the data collected in the study.

\section{Experimental setup and procedure}

The experimental rig used for this study is divided into two main sections: the test loop with the R134a refrigerant and the secondary loop which uses R404a to cool the test loop. The test loop, depicted in Fig.1, includes the test section, R134a tank, gear pump, sub-cooler, two Coriolis flow meters (accuracy of $\pm 0.1 \%$ ), pre-heater, and condenser. Upstream the test section, three sight glasses were installed to confirm that there is no flow boiling in the pre-heater and two $25 \mu \mathrm{m}$ 
inline filters are used to prevent any possible sediment to enter the test section. The test section, shown in Fig. 2.a, is made of oxygen free copper where 26 rectangular micro channels were produced on the top surface using a CNC (Computer Numerical Control) machine. The dimensions of the copper block are $15 \mathrm{~mm}$ width, $20 \mathrm{~mm}$ length (i.e. 300 $\mathrm{mm}^{2}$ in the base area) and $74 \mathrm{~mm}$ height The design dimensions of the micro channel are $350 \mu \mathrm{m}$ width (Wch), $630 \mu \mathrm{m}$ depth (Hch), $200 \mu \mathrm{m}$ fin thickness (Wth) and $2000 \mu \mathrm{m}$ length (L) (Fig.2.b).

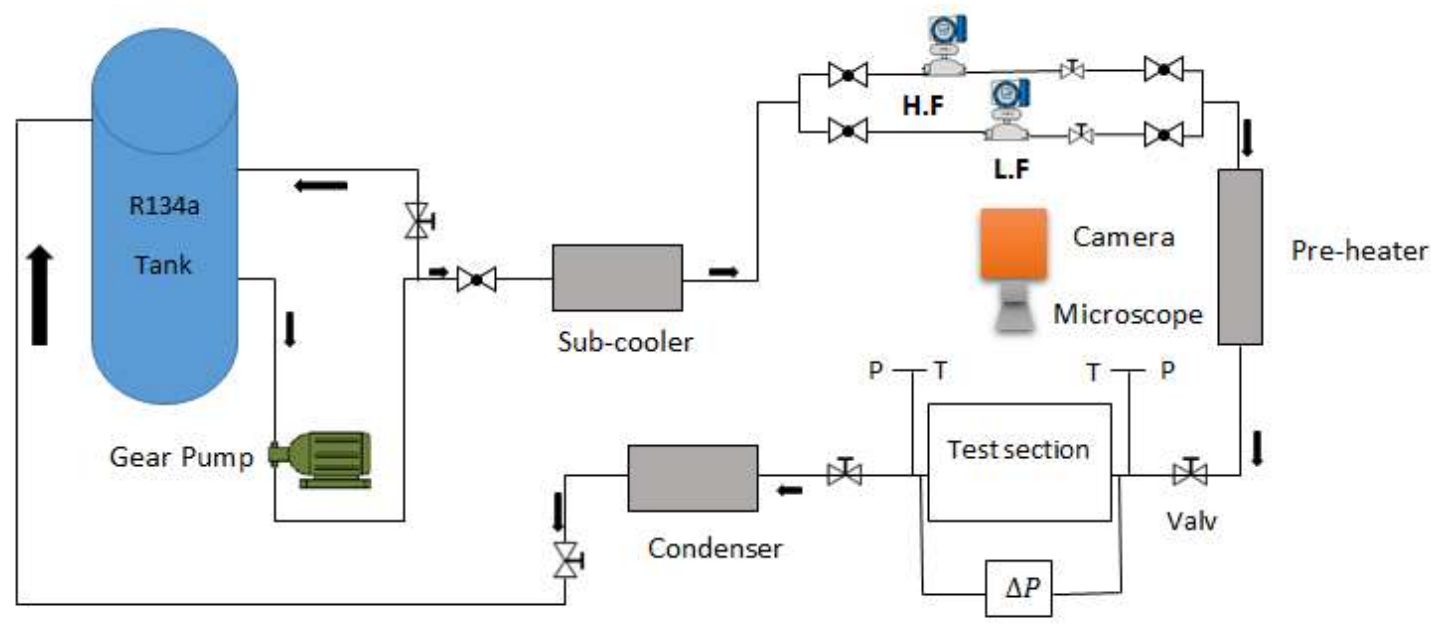

Fig. 1: Schematic of the experimental test rig.

The values measured with an electron scan microscope were $\mathrm{W}_{\mathrm{ch}}=348 \mu \mathrm{m}, \mathrm{H}_{\mathrm{ch}}=627 \mu \mathrm{m}$ and $\mathrm{W}_{\mathrm{th}}=209 \mu \mathrm{m}$ which were used in the following calculations. The value of the relative surface roughness of the bottom wall, measured with a Zygo NewView 5000 surface profiler, was $0.245 \mu \mathrm{m}$. The test section was inserted inside a housing which comprises two parts: i) a polycarbonate top section that includes the inlet/outlet manifolds, an $8 \mathrm{~mm}$ thick quartz glass top cover plate and plenums and ii) the PTFE (polytetrafluoroethylene) was a synthetic fluoropolymer of tetrafluoroethylene at the bottom. Two O-rings seal the copper block inserted into the housing. The inlet/outlet manifold had the same depth a small difference between the two of $0.087 \%$. Heating to the test section was achieved with three cartridge heaters of 175 $\mathrm{W}$ power each, inserted at the bottom of the copper block. Heating power was controlled by a variac and measured with power meter Hameg HM8115-2 with an error of $\pm 0.37 \%$.

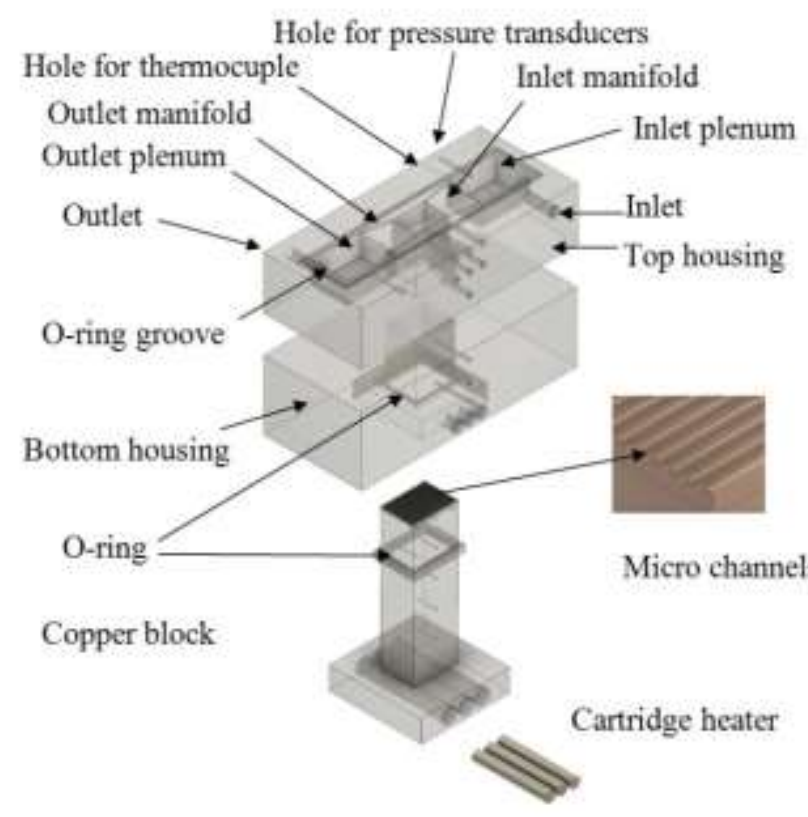

(a)

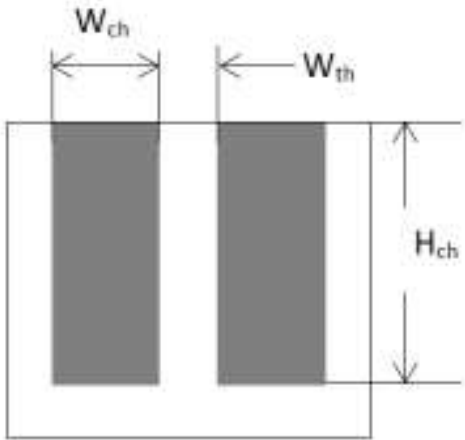

(b)

Fig. 2: (a) Schematic of the test section and (b) channel geometry. 
Starting from the top side of the copper block, three T-type thermocouples $10 \mathrm{~mm}$ apart (row parallel to the flow direction) were inserted at $2.7 \mathrm{~mm}$ distance from the channel bottom wall. These thermocouples were used to determine the local heat transfer coefficient. Another row of three T-type thermocouples was inserted at $12 \mathrm{~mm}$ distance from the top row to make sure that there was no axial heat conduction in the copper block. Four additional T-type thermocouples (12 mm apart) were inserted at $12 \mathrm{~mm}$ from the second row in the vertical direction at the centreline of the copper block. This arrangement provides six vertical thermocouples along the centreline of the copper block, which were used to determine q" base heat flux. All the thermocouples had a $0.5 \mathrm{~mm}$ diameter and were calibrated with an approximate accuracy of $\pm 0.14 \mathrm{~K}$. To measure the inlet and outlet temperature of the test fluid, T-type thermocouples of $1 \mathrm{~mm}$ in diameter, calibrated at $\pm 0.15 \mathrm{~K}$, accuracy were used. Absolute pressure transducers were set immediately before and after the test section to measure the fluid inlet and outlet pressure with an accuracy of $\pm 0.18 \%$ and $\pm 0.41 \%$ respectively. For flow visualization, a high-speed camera Phantom V.6 with $1000 \mathrm{f} / \mathrm{s}$ at full resolution $512 \times 512$ pixels and $32000 \mathrm{f} / \mathrm{s}$ at $256 \times 256$ pixels was coupled with a microscope.

The experimental procedure started once the system pressure reached the set value of 7 bar. The data was recorded, when the system reached steady state (constant readings with only small oscillations), using IMP3595 data acquisition system and a LabVIEW program. During the experiments, the flow rate was kept constant and the heating power was gradually increased. Data for each experiment were recorded for $2 \mathrm{~min}$ at a frequency of $1 \mathrm{~Hz}$. The average value of this data was used in the data reduction process.

\section{Data reduction}

The experimentally determined single phase fanning friction factor, $\mathrm{f}_{\text {exp }}$, is calculated as:

$$
\mathrm{f}_{\exp }=\frac{\Delta \mathrm{P}_{\mathrm{ch}} * \mathrm{D}_{\mathrm{h}}}{2 \mathrm{~L} * \mathrm{v}_{\mathrm{f}} * \mathrm{G}^{2}}
$$

where $\mathrm{D}_{\mathrm{h}}$ is the hydraulic diameter, $\mathrm{L}$ channel length, $\mathrm{v}_{\mathrm{f}}$ liquid specific volume $\left(\mathrm{kg} / \mathrm{m}^{3}\right)$ and $\mathrm{G}$ is the mass flux and $\Delta \mathrm{P}_{\mathrm{ch}}$ is the pressure drop along a micro channel, i.e.:

$$
\Delta \mathrm{P}_{\mathrm{ch}}=\Delta \mathrm{P}_{\mathrm{m}}-\Delta \mathrm{P}_{\text {loss }}
$$

where $\Delta \mathrm{P}_{\mathrm{m}}$ is the total measured pressure drop, $\Delta \mathrm{P}_{\text {loss }}$ is the total pressure loss calculated as:

$$
\Delta \mathrm{P}_{\text {loss }}=\Delta \mathrm{P}_{\mathrm{mi}}+\Delta \mathrm{P}_{\mathrm{sc}}+\Delta \mathrm{P}_{\mathrm{ex}}+\Delta \mathrm{P}_{\mathrm{mo}}
$$

In Eq. (3), $\Delta \mathrm{P}_{\mathrm{mi}}$ is the inlet manifold term, $\Delta \mathrm{P}_{\mathrm{mo}}$ is the outlet manifold term, $\Delta \mathrm{P}_{\mathrm{sc}}$ is the sudden contraction term, and $\Delta \mathrm{P}_{\mathrm{ex}}$ is the sudden expansion term. The components of the pressure loss in the above equation are given below [22]:

$$
\begin{gathered}
\Delta \mathrm{P}_{\mathrm{mi}}=\left[1-\sigma^{2}+\mathrm{K}_{\mathrm{mi}}\right] \times \frac{1}{2} \mathrm{G}^{2} \mathrm{v}_{\mathrm{f}} \\
\Delta \mathrm{P}_{\mathrm{mo}}=-\left[\frac{1}{\sigma^{2}}-1+\mathrm{K}_{\mathrm{mo}}\right] \times \frac{1}{2} \mathrm{G}^{2} \mathrm{v}_{\mathrm{f}}
\end{gathered}
$$

where $\mathrm{K}_{\mathrm{mi}}$ and $\mathrm{K}_{\mathrm{mo}}$ are the loss coefficients (respectively 0.134 and 0.11 ) which depend on the manifold convergence and divergence angle $\theta$ as a function of the area ratio $\sigma$ and angle $\theta$ [23]. In the equations above, $\sigma=0.714$ is the small to large cross sectional area ratio. The sudden contraction and expansion loss in Eq. (3) are given by the following [24]:

$$
\begin{aligned}
& \Delta \mathrm{P}_{\mathrm{sc}}=\left[1-\sigma^{2}+0.5(1-\sigma)\right] \frac{1}{2} \mathrm{G}^{2} \mathrm{v}_{\mathrm{f}} \\
& \Delta \mathrm{P}_{\mathrm{ex}}=-\left[\frac{1}{\sigma^{2}}-1+(1-\sigma)^{2}\right] \frac{1}{2} \mathrm{G}^{2} \mathrm{v}_{\mathrm{f}}
\end{aligned}
$$

The local heat transfer coefficient for single phase and two-phase flow is calculated by: 


$$
\begin{gathered}
h_{s p(z)}=\frac{\mathrm{q}^{\prime \prime}\left(\mathrm{W}_{\mathrm{ch}}+\mathrm{W}_{\mathrm{fin}}\right)}{\left(\mathrm{T}_{\mathrm{wi}(\mathrm{z})}-\mathrm{T}_{\mathrm{f}(\mathrm{z})}\right)\left(\mathrm{W}_{\mathrm{ch}}+2 \eta \mathrm{H}_{\mathrm{ch}}\right)} \\
h_{t p(z)}=\frac{\mathrm{q}^{\prime \prime}\left(\mathrm{W}_{\mathrm{ch}}+\mathrm{W}_{\mathrm{fin}}\right)}{\left(\mathrm{T}_{\mathrm{wi}(\mathrm{z})}-\mathrm{T}_{\mathrm{sat}(\mathrm{z})}\right)\left(\mathrm{W}_{\mathrm{ch}}+2 \eta \mathrm{H}_{\mathrm{ch}}\right)}
\end{gathered}
$$

where, $\mathrm{q}^{\prime}$ is the base heat flux, $\mathrm{W}_{\mathrm{ch}}$ is channel width, $\mathrm{W}_{\text {fin }}$ is the fin width, $\mathrm{T}_{\mathrm{wi}(\mathrm{z})}$ is the local internal surface temperature, $\eta$ is the fin efficiency. The local pressure at the beginning of the saturated region $P_{-}(\operatorname{sat}(z, s u b))$ is calculated to find the local saturation temperature Tsat(z).

$$
\begin{gathered}
\mathrm{q}^{\prime \prime}=K_{c} \frac{d T}{d y} \\
\mathrm{~T}_{\mathrm{wi}(\mathrm{z})}=\mathrm{T}_{\mathrm{th}(\mathrm{z})}-\frac{\mathrm{q}^{\prime \prime} * \mathrm{~d}}{\mathrm{kc}} \\
\mathrm{T}_{\mathrm{f}(\mathrm{z})}=\mathrm{T}_{\text {fin }}-\frac{\mathrm{q}^{\prime \prime} * \mathrm{~W} * \mathrm{z}}{\dot{\mathrm{m}} * \mathrm{cp}_{\mathrm{f}}}
\end{gathered}
$$

where $T_{\text {th(z) }}$ is the local thermocouple temperature, $d$ is the vertical distance, $T_{f(z)}$ the local fluid temperature,$T_{\text {fin }}$ the fluid inlet temperature, $\mathrm{z}$ the horizontal local distance.

$$
\begin{gathered}
P_{\text {sat }(\mathrm{z})}=P_{\text {sat }(z, s u b)}-\left(\frac{z-L_{\text {sub }}}{L_{c h}-L_{s u b}}\right) * \Delta P_{t p} \\
\mathrm{~L}_{\text {sub }}=\frac{\dot{\mathrm{m}} * c p_{f}\left(T_{s a t(z, s u b)}-T_{\mathrm{fin}}\right)}{\mathrm{q}^{\prime} * \mathrm{~W}} \\
\mathrm{P}_{\mathrm{sat}(\mathrm{z}, \mathrm{sub})}=\mathrm{P}_{\mathrm{fin}}-\frac{2 f * G_{c h}^{2} * \mathrm{~L}_{s u b}}{\rho_{\mathrm{f}} * D_{h}} \\
\Delta P_{t p}=\Delta P_{c h}-\Delta P_{s p}
\end{gathered}
$$

To account for the fact that only three of the four sides of the channels were heated, the following relations are used to correct the heat transfer coefficient [25-30]:

$$
\mathrm{h}_{\mathrm{cf}}=\left(\frac{\mathrm{Nu} 3}{\mathrm{Nu} 4}\right) h_{t p}
$$

where $\mathrm{Nu} 3$ and $\mathrm{Nu} 4$ are Nusselt number for thermally developed laminar flow with three-sided and four-sided heat transfer, respectively. The values Nu3 and Nu4 are found from Eq. (16) and (17) using [30]:

$$
\begin{gathered}
\mathrm{Nu} 3=8.235\left(1-1.8333 \alpha+3.767 \alpha^{2}-5.814 \alpha^{3}+5.361 \alpha^{4}-2 \alpha^{5}\right) \\
\mathrm{Nu} 4=8.235\left(1-2.042 \alpha+3.085 \alpha^{2}-2.477 \alpha^{3}+1.058 \alpha^{4}-0.186 \alpha^{5}\right)
\end{gathered}
$$

where $\alpha$ is the aspect ratio, calculated as the ratio between the channel width, $\mathrm{W}_{\mathrm{ch}}$, and the channel height, $\mathrm{H}_{\mathrm{ch}}$.

\section{Results and discussions}

Single phase experiments were performed to verify the experimental setup, procedures and measurements before running tests in two-phase flow. The following sections describe the results obtained in both cases. 


\subsection{Single phase validation}

The experimental tests were run at a system pressure $6.5 \mathrm{bar}$, mass flux ranging between $100-1900 \mathrm{~kg} / \mathrm{m}^{2} \mathrm{~s}$ and heat flux fixed at $21.01 \mathrm{~kW} / \mathrm{m}^{2}$. Fig 3.a reports the measured friction factor compared to predictions of correlations for developing and fully developed flow by Shah and London [30]. The comparison shows that the two correlations slightly under predict the friction factor, albeit the difference is within the experimental error. Fig 3.b shows a good agreement between Re and the experimental Nusselt number with the correlations by Stephan and Preuber [31].

\subsection{Two-Phase Flow Results}

The experiments in two-phase flow were performed at system pressure of $7 \mathrm{bar}$, heat flux range $7.6-480.5 \mathrm{~kW} / \mathrm{m}^{2}$ and mass flux range $50-300 \mathrm{~kg} / \mathrm{m}^{2} \mathrm{~s}$.

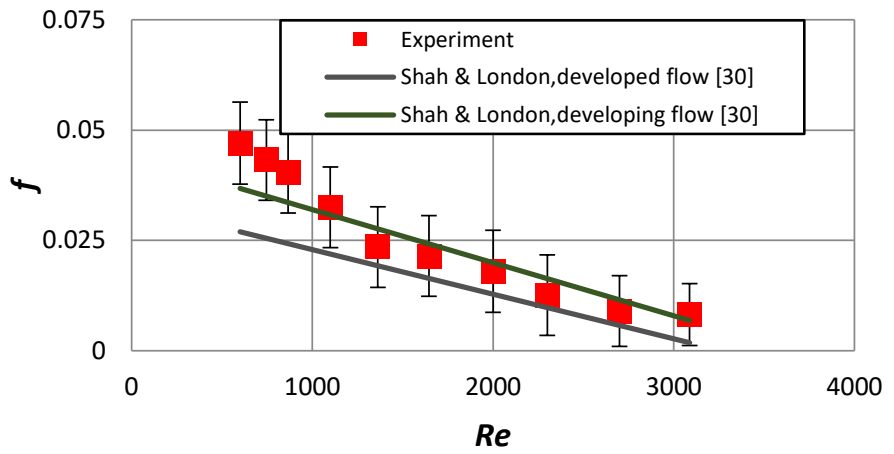

(a)

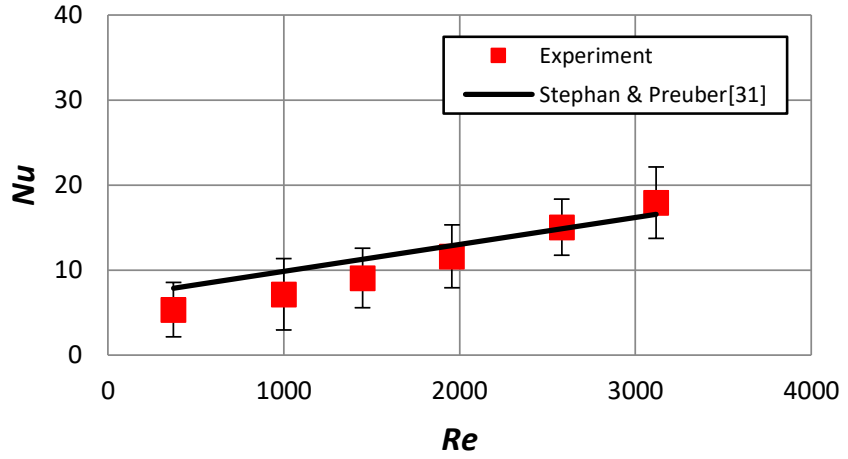

(b)

Fig. 3: Single phase results: (a) Fanning friction factor and (b) Nusselt number versus Reynolds number.

\subsection{Flow Boiling Patterns}

Flow boiling patterns were visualized as described in Section 0 at three different locations; the channel inlet, the middle section and the outlet. Fig. 4 shows the four different flow patterns observed for mass flux $100 \mathrm{~kg} / \mathrm{m}^{2} \mathrm{~s}$ along three of the 26 channels in the middle. At low heat flux $\left(66 \mathrm{~kW} / \mathrm{m}^{2}\right)$, bubbly flow is observed (Fig. 4a). As the heat flux was increased, slug/confined bubbly flow (Fig. 4b) and churn flow (Fig. 4c) appeared. At larger heat flux values ( $\left.256 \mathrm{~kW} / \mathrm{m}^{2}\right)$ annular flow was established (Fig. 4d).

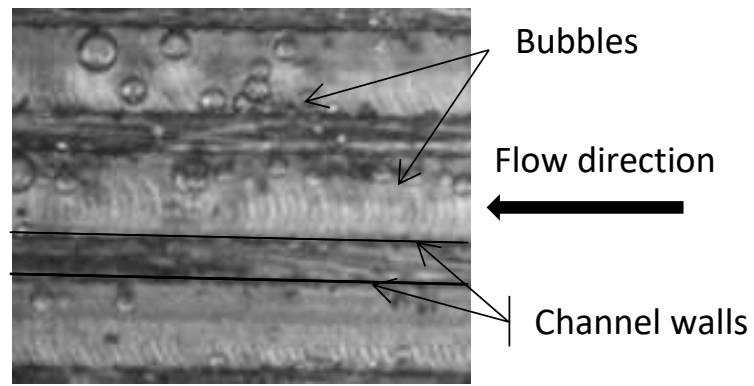

(a) Bubbly flow (heat flux $66 \mathrm{~kW} / \mathrm{m}^{2}$ )

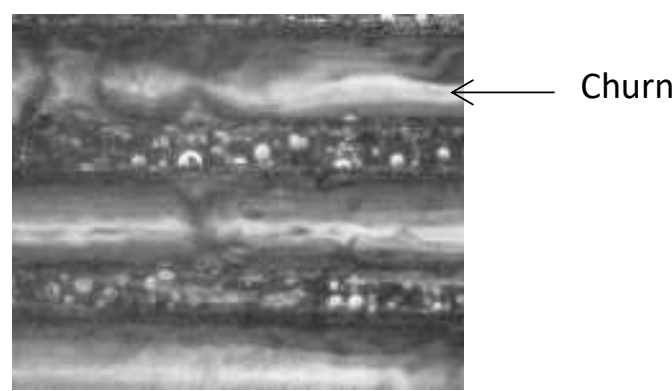

(c) Churn flow $\left(194 \mathrm{~kW} / \mathrm{m}^{2}\right)$

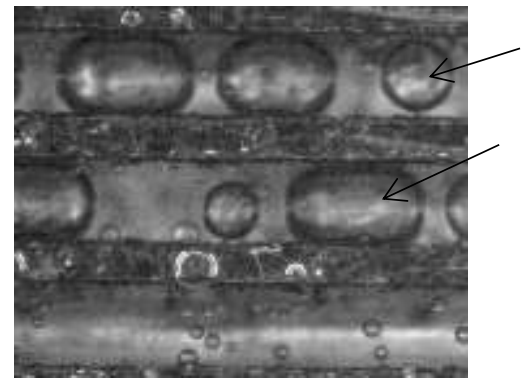

Bubbles

Slug/confined

bubble

b) Slug flow/confined bubble flow $\left(129 \mathrm{~kW} / \mathrm{m}^{2}\right)$

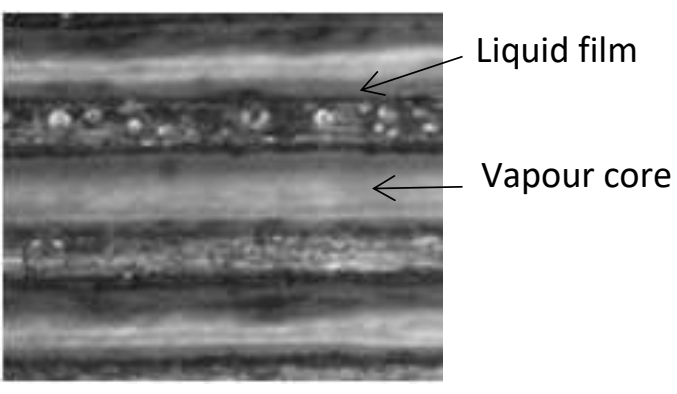

(d) Annular flow $\left(256 \mathrm{~kW} / \mathrm{m}^{2}\right)$

Fig. 4: Observed flow patterns for $100 \mathrm{~kg} / \mathrm{m}^{2} \mathrm{~s}$ mass flux in the mid. 


\subsection{Two-Phase Heat Transfer}

Fig. 5a reports the effect of heat flux on the two-phase heat transfer coefficient versus vapour quality, for three different locations in the test section. The heat transfer coefficient increased with heat flux with small dependency on vapour quality. The highest value of heat transfer coefficient achieved was $35.52 \mathrm{~kW} / \mathrm{m}^{2} \mathrm{~K}$. Fig. $5 . \mathrm{b}$ reports the effect of mass flux on the two-phase heat transfer coefficient, calculated at three different locations of the heat sink. The results demonstrate that there is no effect of mass flux on the heat transfer coefficient.

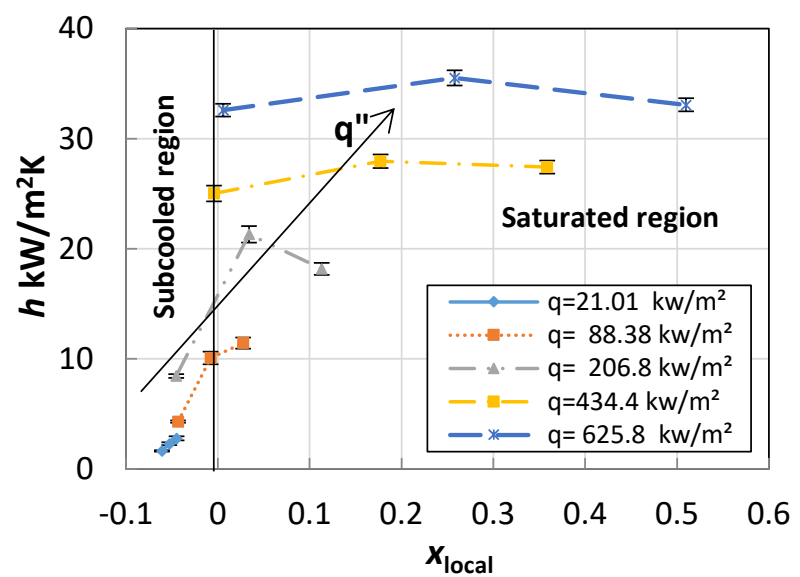

(a)

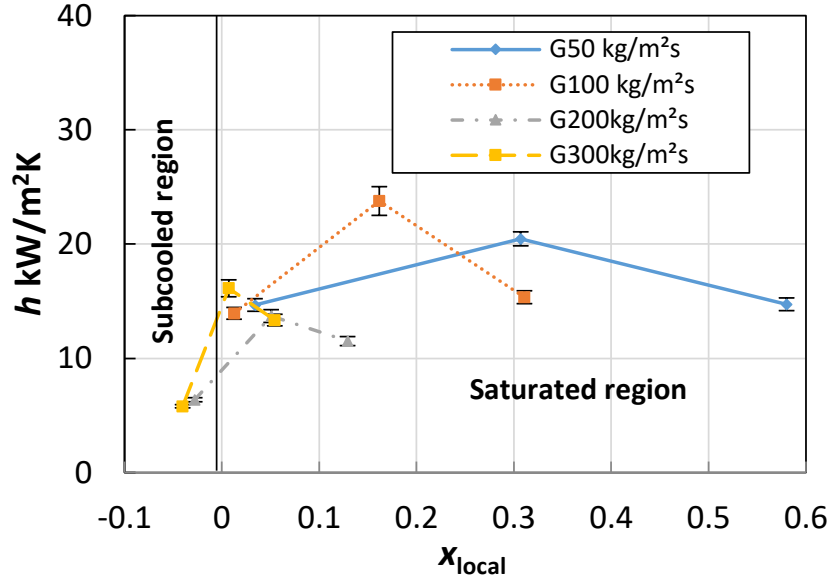

(b)

Fig. 5: Effect of (a) heat flux at $\mathrm{G}=300 \mathrm{~kg} / \mathrm{m}^{2} \mathrm{~s}$ and (b) mass flux at $\mathrm{q}=120 \mathrm{~kW} / \mathrm{m}^{2}$ heat flux on local HTC.

\subsubsection{Evaluation of existing correlations}

The predictions of four existing heat transfer correlations [32-34] were compared to the data collected in this work. Accuracy of the predictions was established by calculating $p$, the percentage of data points predicted within $\pm 30 \%$ error bands:

and the mean absolute error, MAEp:

$$
p=\mathrm{N}_{\text {pred }} / \mathrm{N}_{\mathrm{exp}} \cdot 100 \%
$$

$$
M A E p=\frac{1}{\mathrm{~N}_{\mathrm{pt}}}\left|\left(h_{\text {pred }}-h_{\text {exp }}\right) / h_{\text {exp }}\right| \cdot 100 \%
$$

where $\mathrm{N}_{\mathrm{pt}}$ is the number of data points. Specific values of $p$ and MAE for each of the correlations are shown in Fig.6.

Warrier [33]

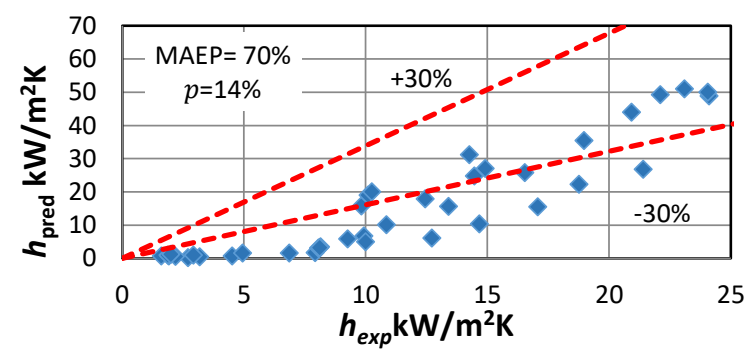

Cooper [35]

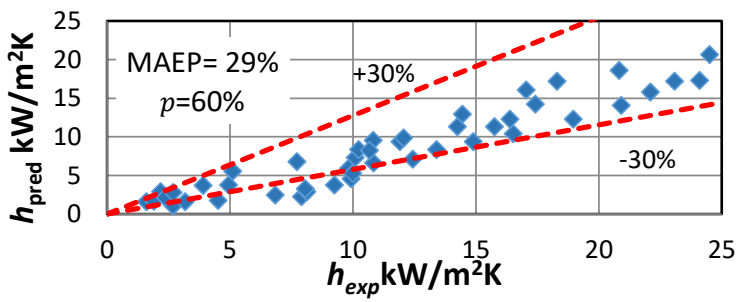

$\mathrm{Li}$ and $\mathrm{Wu}[34]$

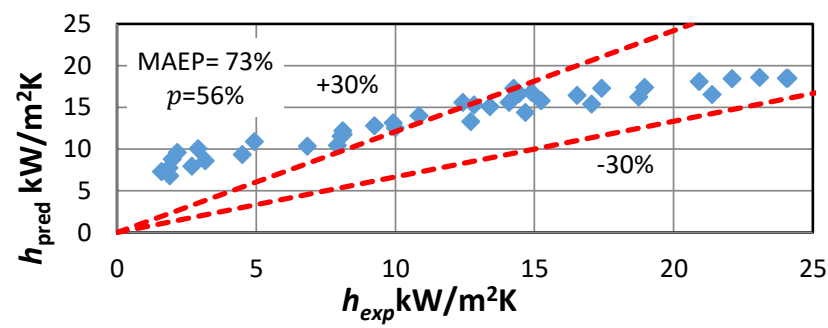

Mahmoud and Karaviannis [321

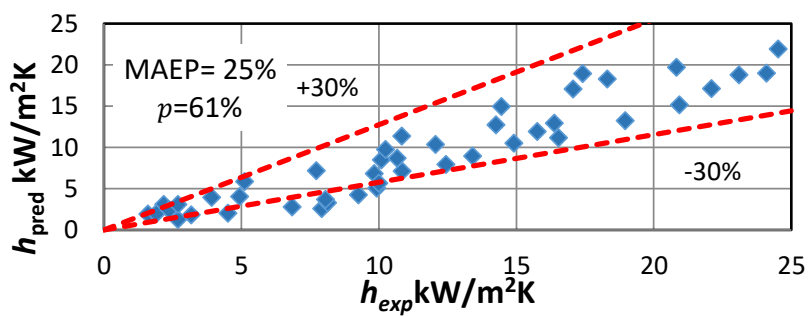

Fig. 6: Comparison with existing heat transfer correlations developed for macro/micro channels.

HTFF 133-6 
The correlation by Warrier [33], developed using FC-84 on a test section consisting of five rectangular channels with hydraulic diameter $\mathrm{D}_{\mathrm{h}} 0.75 \mathrm{~mm}$, shows high values for MAEP (70\%) and $p(14 \%)$. The correlation by $\mathrm{Li}$ and $\mathrm{Wu}$ [34] resulted in lower MAEP (37\%) and higher values of $p(56 \%)$. This correlation was developed for flow boiling in multi and single micro/mini-channels, using an extensive database containing 769 data points and covering 12 fluids including R134a - for a wide range of operating conditions and channel dimensions. Two other correlations by Cooper [35] and Mahmoud and Karayiannis [32] were tested showing a good agreement with the data (MAE value of 29\% and $25 \%$ respectively and relatively high values of $p, 60 \%$ and $61 \%$ respectively).

\section{Conclusions}

This paper reportes the results of flow boiling experiments with R134a in a copper multi-microchannel heat sink for a mass flux range $50-300 \mathrm{~kg} / \mathrm{m}^{2} \mathrm{~s}$, heat flux range $7.6-480.5 \mathrm{~kW} / \mathrm{m}^{2}$ and pressure system $7 \mathrm{bar}$. Data presented show that the heat transfer coefficient increased with increasing heat flux and that there was no mass flux effect. Four flow boiling patterns (bubbly, slug flow/confined bubble flow, churn and annular flow) were observed by using a high-speed highresolution camera. Relevant literature correlations were tested against the data collected, showing that the correlations by Mahmoud and Karayiannis [32] and Cooper [35] predicted the data with a MAEP less than 29\%.

\section{Nomenclature}

$\mathrm{D}$

$\mathrm{D}_{\mathrm{h}}$

$f_{\text {exp }}$

G

$\mathrm{H} \quad$ heat transfer coefficient $[\mathrm{W} / \mathrm{m} 2 \mathrm{~K}]$

$\mathrm{h}_{\exp } \quad$ experimental heat transfer coefficient $[\mathrm{W} / \mathrm{m} 2$

$$
\mathrm{K}]
$$

$\mathrm{h}_{\text {pred }} \quad$ predicted heat transfer coefficient $[\mathrm{W} / \mathrm{m} 2 \mathrm{~K}]$

$\mathrm{H}_{\mathrm{ch}} \quad$ channel height [m]

$\mathrm{K}_{\mathrm{mi}} \quad$ inlet manifold loss coefficient [-]

$\mathrm{K}_{\mathrm{mo}} \quad$ outlet manifold loss coefficient [-]

$\mathrm{k}_{\mathrm{f}} \quad$ liquid thermal conductivity [W/m K]

$\mathrm{L} \quad$ channel length [m]

$M A E \mathrm{P}$ the mean absolute error[-]

$\mathrm{N}$ number of channels, number of data points

$\mathrm{Nu} \quad$ Nusselt number [-]

Nu3 Nusselt number for three-sided heating [-]

$\mathrm{Nu} 4 \quad$ Nusselt number for four-sided heating [-]

$\mathrm{Z} \quad$ the horizontal local distance [m]

\begin{tabular}{|ll}
$\Delta \mathrm{p}_{\mathrm{sc}}$ & pressure drop due to sudden contraction [Pa] \\
$\Delta \mathrm{p}_{\mathrm{ex}}$ & pressure drop due to sudden expansion [Pa] \\
$\Delta \mathrm{p}_{\text {loss }}$ & pressure losses [Pa] \\
$\Delta \mathrm{p}_{\mathrm{mi}}$ & pressure drop in the inlet manifold [Pa] \\
$\Delta \mathrm{p}_{\mathrm{m}}$ & measured pressure drop [Pa] \\
$\mathrm{q}^{\prime \prime}$ & base heat flux [W/m2] \\
& \\
$\mathrm{T}_{\mathrm{f}, \mathrm{in}}$ & fluid inlet temperature [K] \\
$\mathrm{T}_{\mathrm{f}}$ & fluid temperature [K] \\
$\mathrm{T}_{\mathrm{w}, \mathrm{m}}$ & wall temperature at mid location $[\mathrm{K}]$ \\
$\mathrm{T}_{\mathrm{w}, \mathrm{thm}}$ & thermocouple temperature at mid location $[\mathrm{K}]$ \\
$\mathrm{v}_{\mathrm{f}}$ & specific volume of saturated liquid [m3/kg] \\
$\mathrm{W}$ & heat sink width [m] \\
$\mathrm{W}_{\mathrm{ch}}$ & channel width [m] \\
$\Delta$ & the small to large cross sectional area ratio[-] \\
$\Theta$ & manifold convergence and divergence angle [ $\left.{ }^{\circ}\right]$ \\
$\mathrm{A}$ & aspect ratio [-] \\
$\mathrm{H}$ & fin efficiency [-]
\end{tabular}

\section{References}

[1] M. E. Steinke and S. G. Kandlikar, "An Experimental Investigation of Flow Boiling Characteristics of Water in Parallel Microchannels," J. Heat Transfer, vol. 126, pp. 518-526, 2004.

[2] M. Hamdar, A. Zoughaib, and D. Clodic, "Flow boiling heat transfer and pressure drop of pure HFC-152a in a horizontal mini-channel," Int. J. Refrig., vol. 33, pp. 566-577, 2010.

[3] Z. Anwar, B. Palm, and R. Khodabandeh, "Flow boiling heat transfer and dryout characteristics of R152a in a vertical mini-channel," Exp. Therm. Fluid Sci., vol. 53, pp. 207-217, 2014.

[4] W. Qu and I. Mudawar, "Flow boiling heat transfer in two-phase micro-channel heat sinks-I. Experimental investigation and assessment of correlation methods," Int. J. Heat Mass Transf., vol. 46, pp. 2755-2771, 2003.

[5] S. Mortada, A. Zoughaib, C. Arzano-Daurelle, and D. Clodic, "Boiling heat transfer and pressure drop of R134a and R-1234yf in minichannels for low mass fluxes," Int. J. Refrig., vol. 35, pp. 962-973, 2012.

[6] V. V. Kuznetsov, A. S. Shamirzaev, I. A. Kozulin, and S. P. Kozlov, "Correlation of the flow pattern and flow boiling heat transfer in microchannels," Heat Transf. Eng., vol. 34, no. 2-3, pp. 235-245, 2013.

[7] D. A. McNeil, A. H. Raeisi, P. A. Kew, and R. S. Hamed, "Flow boiling heat-transfer in micro to macro transition flows," Int. J. Heat Mass Transf., vol. 65, pp. 289-307, 2013. 
[8] M. M. Mahmoud, T. G. Karayiannis, and D. B. R. Kenning, "Surface effects in flow boiling of R134a in microtubes," Int. J. Heat Mass Transf., vol. 54, pp. 3334-3346, 2011.

[9] T. G. Karayiannis, M. M. Mahmoud, and D. B. R. Kenning, "A study of discrepancies in flow boiling results in small to microdiameter metallic tubes," Exp. Therm. Fluid Sci., vol. 36, pp. 126-142, 2012.

[10] B. Markal, O. Aydin, and M. Avci, "Effect of aspect ratio on saturated flow boiling in microchannels," Int. J. Heat Mass Transf., vol. 93, pp. 130-143, 2016.

[11] L. Consolini and J. R. Thome, "Micro-channel flow boiling heat transfer of R-134a, R-236fa, and R-245fa," Microfluid. Nanofluidics, vol. 6, pp. 731-746, 2009.

[12] H. Ohta, K. Inoue, M. Ando, and K. Watanabe, "Experimental investigation on observed scattering in heat transfer characteristics for flow boiling in a small diameter tube," Heat Transf. Eng., vol30, no1-2,19-27,2009.

[13] T. N. Tran, M. W. Wambsganss, and D. M. France, "Small circular- and rectangular-channel boiling with two refrigerants," Int. J. Multiph. Flow, vol. 22, no. 3, pp. 485-498, 1996.

[14] Z. Y. Bao, D. F. Fletcher, and B. S. Haynes, "Flow boiling heat transfer of Freon R11 and HCFC123 in narrow passages," Int. J. Heat Mass Transf., vol. 43, pp. 3347-3358, 2000.

[15] X. Huo, L. Chen, Y. S. Tian, and T. G. Karayiannis, "Flow boiling and flow regimes in small diameter tubes," Appl. Therm. Eng., vol. 24, pp. 1225-1239, 2004.

[16] J. Pettersen, "Flow vaporization of CO2in microchannel tubes," Exp. Therm. Fluid Sci.,vol. 28, 111-121, 2004.

[17] S. Saitoh, H. Daiguji, and E. Hihara, "Effect of tube diameter on boiling heat transfer of R-134a in horizontal small-diameter tubes," Int. J. Heat Mass Transf., vol. 48, pp. 4973-4984, 2005.

[18] R. Yun, Y. Kim, and M. S. Kim, "Flow boiling heat transfer of carbon dioxide in horizontal mini tubes," Int. J. Heat Fluid Flow, vol. 26, pp. 801-809, 2005.

[19] R. Yun, Y. Kim, and M. S. Kim, "Convective boiling heat transfer characteristics of CO2in microchannels," Int. J. Heat Mass Transf., vol. 48, pp. 235-242, 2005.

[20] B. Sumith, F. Kaminaga, and K. Matsumura, "Saturated flow boiling of water in a vertical small diameter tube," Exp. Therm. Fluid Sci., vol. 27, pp. 789-801, 2003.

[21] E. M. Fayyadh, M. M. Mahmoud, K. Sefiane, and T. G. Karayiannis, "Flow boiling heat transfer of R134a in multi microchannels," Int. J. Heat Mass Transf., vol. 110, pp. 422-436, 2017.

[22] R. Remsburg, Thermal Design of Electronic Equipment. 2000.

[23] J. P. S. Edward J. Shaughnessy, Jr., Ira M. Katz, “INTRODUCTION TO FLUID MECHANICS,”vol. 60, no. 1, pp. 125-133, 2005.

[24] R. Remsburg, M. Leap, and R. Remsburg, "Thermal Design Of Electronic Equipment," no. September 2000.

[25] D. B. S. Gawali, V. B. Swami, and S. D. Thakre, "Theoretical and Experimental Investigation of Heat Transfer Characteristics through a Rectangular Microchannel Heat Sink," Int. J. Innov. Res. Sci. Eng. Technol., vol. 3, no. 8, pp. 15631-15640, 2014.

[26] S. Kim and I. Mudawar, "International Journal of Heat and Mass Transfer Flow condensation in parallel microchannels,Part2 : Heat transfer results and correlation technique," Int. J. H. M. T., vol.55, 984-994, 2012.

[27] S. Kim and I. Mudawar, "International Journal of Heat and Mass Transfer Review of databases and predictive methods for heat transfer in condensing and boiling mini / micro-channel flows," ., vol. 77, 627-652, 2014.

[28] W. Qu and I. Mudawar, "Flow boiling heat transfer in two-phase micro-channel heat sinks - II . Annular twophase flow model," vol. 46, pp. 2773-2784, 2003.

[29] J. Lee and I. Mudawar, "Two-phase flow in high-heat-flux micro-channel heat sink for refrigeration cooling applications : Part II — heat transfer characteristics," vol. 48, pp. 941-955, 2005.

[30] R. K. Shah and A. L. London, LAMINAR FLOW FORCED CONVECTION IN DUCTS A Source Book for Compact Heat Exchanger Analytical Data. New York, 1978.

[31] P. P. K. Stephan, "Wärme\} ubergang und maximale wärmstromichte beim behältersieden binärer und ternärer fl\} ussigkeitsgemische," Chem. Ing. Tech., 1979.

[32] M. M. Mahmoud and T. G. Karayiannis, "Heat transfer correlation for flow boiling in small to micro tubes," Int. J. Heat Mass Transf., vol. 66, pp. 553-574, 2013.

[33] G. R. Warrier, V. K. Dhir, and L. A. Momoda, "Heat transfer and pressure drop in narrow rectangular channels," Exp. Therm. Fluid Sci., vol. 26, pp. 53-64, 2002.

[34] W. Li and Z. Wu, "International Journal of Heat and Mass Transfer A general correlation for evaporative heat transfer in micro / mini-channels," Int. J. Heat Mass Transf., vol. 53, pp. 1778-1787, 2010.

[35] M. G. Cooper, "Saturated nucleate pool boiling - a simple correlation," in First UK National Heat Transfer Conference, IChemE Symposium, 1984, pp. 785-793. 